\section{Truly amazing teachers}

Students and vocational dental practitioners (VDPs) can help get outstanding dental teachers recognised by nominating them for Dental Care Professional (DCP) Teacher of the Year, one of the categories in the Dental Defence Union's (DDU's) annual Educational Awards, now in its fifth year. Spots in the categories of DCP Teacher of the Year, Dentist Teacher of the Year and Vocational Teacher of the Year are up for grabs

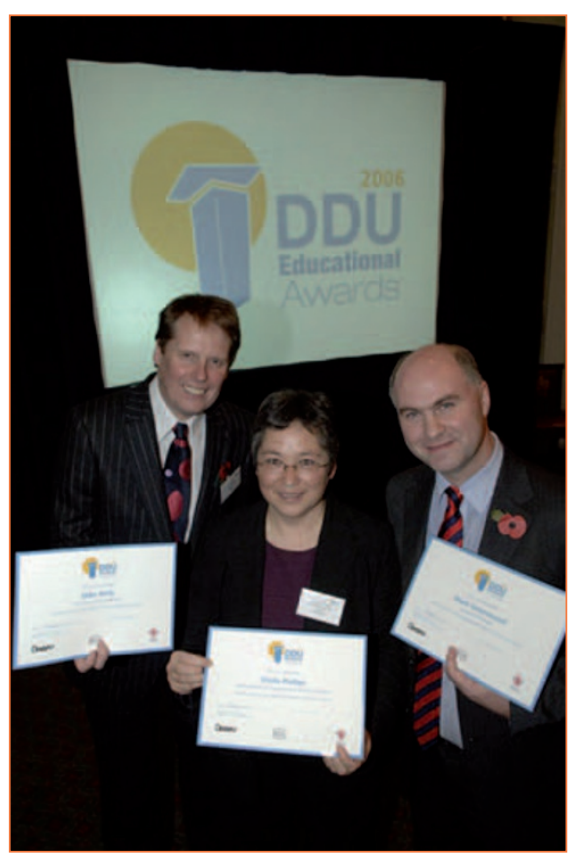

Last year's winners: Mike (left), Sheila and Mark and will be presented at an awards ceremony in London in November. Winners and runners-up will be awarded $\mathfrak{£} 250$ each and in addition, the overall winners in each category will receive $\mathfrak{£} 1,000$ towards the cost of educational materials for their schools or VT schemes.

Students and VDPs in the UK and Ireland can nominate a teacher by completing a nomination form, by 31 July 2007, which is then reviewed by the DDU and a panel of judges. Forms are available on the DDU website (www.the-ddu.com/dduawards) or from a DDU dental liaison manager. Students and VDPs who submit an entry will be entered into a prize draw to win an iPod.

The winner in each category will be chosen following a presentation by finalists at the awards ceremony. Awards will be judged across a number of criteria, including knowledge of the subject and ability to motivate. The DDU awards' main sponsor is Dentsply, while the BDA is also supporting the initiative. The winners of the DDU Educational Awards in 2006 were Mark Greenwood from the University of Newcastle, Mike Kelly from Kent, Surrey and Sussex Deanery and Sheila Phillips of the School of Professionals Complementary to Dentistry, Portsmouth who won Dentist Teacher of the Year, Vocational Trainer of the Year and DCP Teacher of the Year respectively.

\title{
Exam passes for clinical dental technicians
}

The first set of student clinical dental technicians have passed the exams set by the Faculty of General Dental Practice at the Royal College of Surgeons of England and are now in the process of registration as the first Clinical Dental Technicians/Denturists in the UK.

The UK qualifications are only open at present to graduates of George Brown College who have passed the two and a half year long academic and clinical programme. The Clinical Dental Technicians Association is currently progressing towards the building

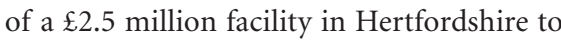
undertake clinical dental technician training wholly within the UK. The shell is currently under construction and a major announcement is expected later this year.

The project will have ten fully serviced dental units, a 25 place dental laboratory, lecture theatres, audio visual and internet distance learning, accommodation and restaurant facilities. There will also be radiography units and a central sterile department as well as patient reception areas and offices. The centre will be available for all members of the dental team for training and continuing professional development as well as providing dental services to the local Primary Care Trust and patients.
Reducing carbon footprints

The British Association of Dental Nurses (BADN) is taking steps to reduce its carbon footprint. It is encouraging communication by email to cut down on the amount of paper used, has replaced its face-to-face June council meeting with a telemeeting to reduce travel, and will be reviewing its conference policies and operations.

The Association has produced its membership information pack and application form in an electronic PDF format, available from its website www. badn.org.uk, which can be circulated to prospective members who then only have to print off the actual form. Prospective members are encouraged to request the e-version rather than a hard copy.

President Michelle Brindley said, 'The impact of carbon emissions on the environment is a matter of increasing concern. The BADN subscribes to the 'Every Action Counts' ethos and is consequently making a concerted effort to review its policies and operations with a view to reducing environmental impact. We are not claiming to be completely green, or carbon neutral, but we feel that even small changes can make a difference.

She added that the Association already has policies at head office regarding recycling of as many materials as possible, including toner and print cartridges, shredding and recycling of waste paper. In the future, it intends to look at other ways to reduce or offset carbon production by encouraging conference delegates to car shares, for example, and more effective use of electronic communications. More information on what you can do to reduce environmental impact is available at www.everyactioncounts.org.uk. 